\title{
Letrozole Determination by Capillary Zone Electrophoresis and UV Spectrophotometry Methods
}

\author{
Aura Rusu1 ${ }^{*}$, Maria-Alexandra Sbanca², Nicoleta Todoran³, Camil-Eugen Vari ${ }^{4}$ \\ 1 Department of Pharmaceutical Chemistry, University of Medicine and Pharmacy of Tîrgu Mureș \\ 2 University of Medicine and Pharmacy of Tîrgu Mureș \\ 3 Department of Pharmaceutical Technology, University of Medicine and Pharmacy of Tîrgu Mures \\ 4 Department of Pharmacology and Clinical Pharmacy, University of Medicine and Pharmacy of Tîrgu Mureș
}

Objective: Letrozole is a highly potent oral nonsteroidal aromatase inhibitor triazole derivative. The aim of this study was to quantify letrozole from bulk, pharmaceutical formulation, and spiked urine samples by developing a simple, rapid and cost effective capillary electrophoresis method. Methods: A capillary zone electrophoresis method was optimized and validated. Additionally, an UV spectrophotometry method was used for comparing results. Results:The capillary zone electrophoresis method using a $90 \mathrm{mM}$ sodium tetraborate background electrolyte proved to be an efficient method for determination of letrozole in a very short time, less than 2 minutes, using $20 \mathrm{kV}$ voltage, $50 \mathrm{mbar} / 2$ seconds pressure and $50^{\circ} \mathrm{C}$ temperature as optimum parameters. Additionally, the UV spectrophotometry method proved to be simple and efficient to quantify letrozole from bulk material and pharmaceutical formulation with linearity of response between 5 to $20 \mu \mathrm{g} \cdot \mathrm{mL}^{-1} \mathrm{concen}$ trations. For both methods, validation parameters, including linearity, detection and quantification limits were determined. Also we proved that our electrophoretic method has potential in analyzing letrozole from biological samples, obtaining encouraging results on estimation of letrozole from spiked urine samples without any special treatment. Conclusions: To quantify letrozole from bulk material, pharmaceutical preparations, and spiked urine samples the capillary zone electrophoresis method using a tetraborate sodium background electrolyte has proven to be simple and appropriate. Also a simple UV spectrophotometric method has been developed and validated for the same purposes.

Keywords: letrozole, aromatase inhibitors, capillary zone electrophoresis, UV spectrophotometry

Received 19 May 2017 / Accepted 20 June 2017

\section{Introduction}

Letrozole (LET) is a nonsteroidal triazole derivative (Figure 1) classified as a highly potent and selective aromatase inhibitors [1] from the third generation. LET inhibits aromatase enzyme which catalyzes the synthesis of estrogens from the androgen precursors. Aromatase expression occurs in many organs, including ovary, placenta, hypothalamus, liver, muscle, adipose tissue, and breast cancer itself. Aromatase catalyzes three separate steroid hydroxylation's which are involved in the conversion of androstenedione (an androgenic precursor) to estrone and testosterone (estrogenic hormones) to estradiol [2-4]. LET offer new treatment options for breast cancer [5]. Unfortunately, LET is

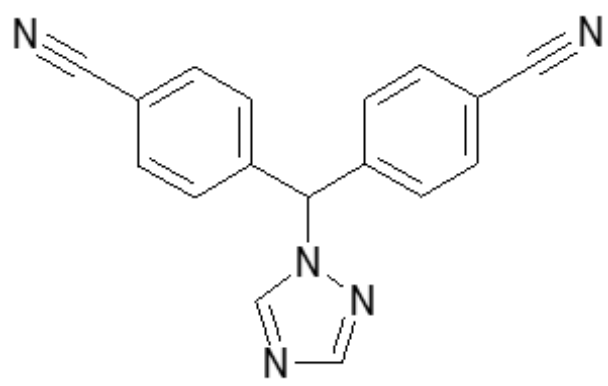

Fig. 1. Letrozole (IUPAC name: 4,4'-((1H-1,2,4-triazol-1-yl)methylene)dibenzonitrile). also used by doped athletes as post cycle therapy in order to promote restoration of hypothalamic-pituitary-testicular axis integrity [6]. A topical issue has emerged with the manufacture of "counterfeit" drugs by unregulated on-line pharmacies, which are tainted with impurities, contain no medication, or are potentially harmful [7].

Biotransformation of LET. LET is completely absorbed from the gastrointestinal tract. The biotransformation occurs by cytochrome P-450 isozymes (CYP2A6 and CYP3A4) into carbinol (Figure 2), an inactive metabolite [8-10]. CYP2A6 isozyme seems to be the principal clearance mechanism for LETin vivo [11].

LET is excreted into urine, approximately $70 \%$ of the administered dose is eliminated as unchanged LET (6.0 \pm $3.8 \%)$ or as the glucuronide of the major, pharmacologically inactive metabolite carbinole (CGP44645) (64.2 \pm $22.7 \%)[13,14]$. Similar data has been previously obtained at the administation of a single dose of letrozole $(2.5 \mathrm{mg})$ with 14C-labeled within two weeks when the recovered radioactivity from urine was $88.2 \pm 7.6 \%(5.0 \pm 2.4 \%$ unmetabolized letrozole, $63.2 \pm 11.2 \%$ carbinole glucuronide and about $8 \%$ other metabolites) [15]. A few capillary electrophoretic (CE) methods for LET determination have been already reported in the literature, mainly micellar electrokinetic capillary chromatographic (MEKC) [1619]. The electrophoretic methods are more advantageous through accessibility than other expensive analytical methods as HPLC and RP-HPLC, LC-MS/MS or SPE-UPLCMS/MS [20-24]. For determination of LET in bulk and 


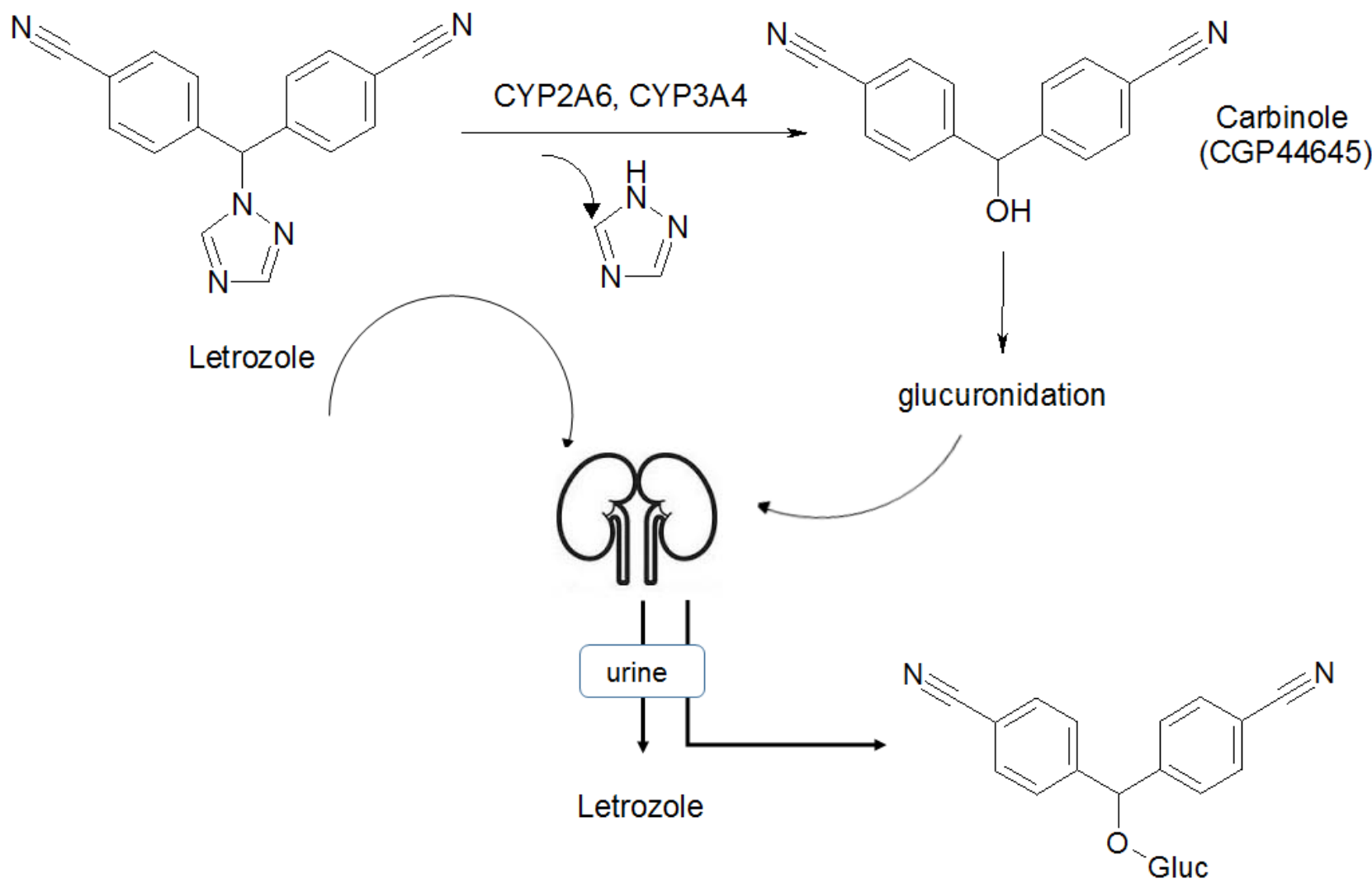

Fig. 2. Biotransformation of LET (*Gluc - glucuronic acid) [12].

pharmaceutical formulations spectrophotometric method are also frequently used [25-27].

The aim of the present study was to develop and validate two simple methods for the determination of LET from bulk materials, pharmaceutical products, and biological samples by capillary zone electrophoresis (CZE) and UV spectrophotometry.

\section{Experimental}

Analytical instruments. The CE experiments were performed on an Agilent $6100 \mathrm{CE}$ system equipped with diode-array detector and results were processed with Chemstation 7.01 software (Agilent). All experiments were performed using a hydrodynamic sample injection. Uncoated fused-silica capillaries of $32.5 \times 50 \mu \mathrm{m}$ I.D (effective length $24,5 \mathrm{~cm}$ ) (Agilent) was used. An Analytik Jena UV-VIS Specord 210 spectrophotometer and WinASPECT software were used for recording UV spectra. The $\mathrm{pH}$ adjustments were performed using a Hanna Instruments HI2215 pH-meter. The spiked urine samples was centrifuged in a Centurion Scientific Ltd. Centrifuge.

Chemicals and reagents. LET was supplied by Sigma Aldrich and ciprofloxacin hydrochloride (CIP) (used as internal standard) by Ranbaxy Laboratories Limited. Pharmaceutical product Letrozole $2.5 \mathrm{mg}$ (tablets) were supplied from Teva. All chemicals and solvents were of analytical reagent grade. The deionized water was obtained using a Millipore Direct-Q ${ }^{\mathrm{TM}}$ system.

Standard stock solution preparation. The LET stock solution was prepared daily at a $1 \mathrm{mg} \mathrm{mL}^{-1}$ con- centration in methanol, treated in an ultrasonic bath for $10 \mathrm{~min}$ at room temperature and stored in the refrigerator at $+4^{\circ} \mathrm{C}$, and diluted to an appropriate concentration with methanol.

Biological samples treatment. Fresh human urine samples were acquired from different healthy volunteers. The urine samples were spiked with LET stock solution, centrifuged (4800 rpm, 10 minutes) and the supernatant was filtrated $(0.45 \mu \mathrm{m}$ Whatman filter). The percentage of solvent (methanol) was identically for all spiked urine samples as the the ratio solvent:urine (1:4).

\section{Methods}

Nowadays, the CZE method is sometimes more attractive comparative to the more frequently used HPLC methods. The main advantages of CZE are: rapid method development, speed of analysis, and relatively low costs derived from the low required amount of sample and reagents [20]. Also, to compare the results we developed a simple and reliable UV spectrophotometry method appliable to estimate the amount of LET in pharmaceutical formulations.

\section{Results and discussion}

\section{A. Capillary zone electrophoresis}

The detection was carried out in UV at $240 \mathrm{~nm}$, in accordance with our recorded UV absorption spectra of LET and data previously reported in literature [25-28]. In CZE capillary preconditioning is necessary for removing adsorbed material from the capillary wall [29]. At the be- 
ginning of each day of experiments the capillary was conditioned with $1 \mathrm{M} \mathrm{NaOH}$ (30 min), deionized water (5 min) and BGE (30 min) than at the beginning of each experiment was preconditioned with water $(1 \mathrm{~min})$ and BGE ( $2 \mathrm{~min})$. The preconditioning before experiments is very important because capillary surface is re-equilibrated by rinsing with BGE [33].

Preliminary considerations. Regarding the $\mathrm{p} K$ a value of LET there are no published studies in the literature. It was found only a calculated pKa value 2.17 (strongest basic) via ChemAxon database [30]. By using MarvinSketch 17.1.2 (ChemAxon) [31] it was found that $\mathrm{pKa}$ of LET is 1.89. LET can accept protons at the nitrogen atoms of the triazole ring. Thus, major microspecies in the range of $\mathrm{pH} 5-13$ are neutral (100\%). It is already known that for conventional CZE method, phosphate and borate buffers can be considered suitable because of their low absorbance at the detection wavelength [32]. Initially, we choose to start with a $25 \mathrm{mM}$ phosphate buffer, an acidic background electrolyte (BGE), but the electrophoretic signal of the substance was difficult to detect (low value of area and height). A standard BGE containing $25 \mathrm{mM}$ borax $(\mathrm{pH}$ 9.3) was than selected, taking in consideration also previous electrophoretic studies, however the disadvantage in a basic environment was that LET migrated very close to the electroosmotic flow (EOF) [16-19]. Adding sodium dodecyl sulfate (SDS) in the $25 \mathrm{mM}$ borax BGE did not resolved the problem.

Optimization of CZE method. To increase the method performance the external parameters such as BGE characteristics (BGE concentration and $\mathrm{pH}$ ) and specific internal capillary electrophoretic system parameters (temperature, injection time, applied voltage, and pressure) were analysed and optimezed in order to improve separation (Figure 3) [33].

Effect of the Ionic Strength of BGE. Generally, the BGE concentration change the electrophoretic behavior of the analytes by influencing the selectivity of separation and EOF velocity [32]. The effect of BGE concentration was studied between $10 \mathrm{mM}$ to $100 \mathrm{mM}$. The increase of the BGE concentration lead to an increase of LET migration times, due to a decrease of EOF with the increase in ionic strength. The $90 \mathrm{mM}$ concentration was set as optimum (best height, area and peak symmetry); the use of BGE with high concentration is limited by the generation of high currents which leads to instability of the electrophoretic system.

Effect of the $p H$ of $B G E$. In order to obtain an adequate peak the variation of $\mathrm{pH}$ was analyzed on a $\mathrm{pH}$ interval between $8.7-10.32$ by adding small amounts of $1 \mathrm{M} \mathrm{NaOH}$
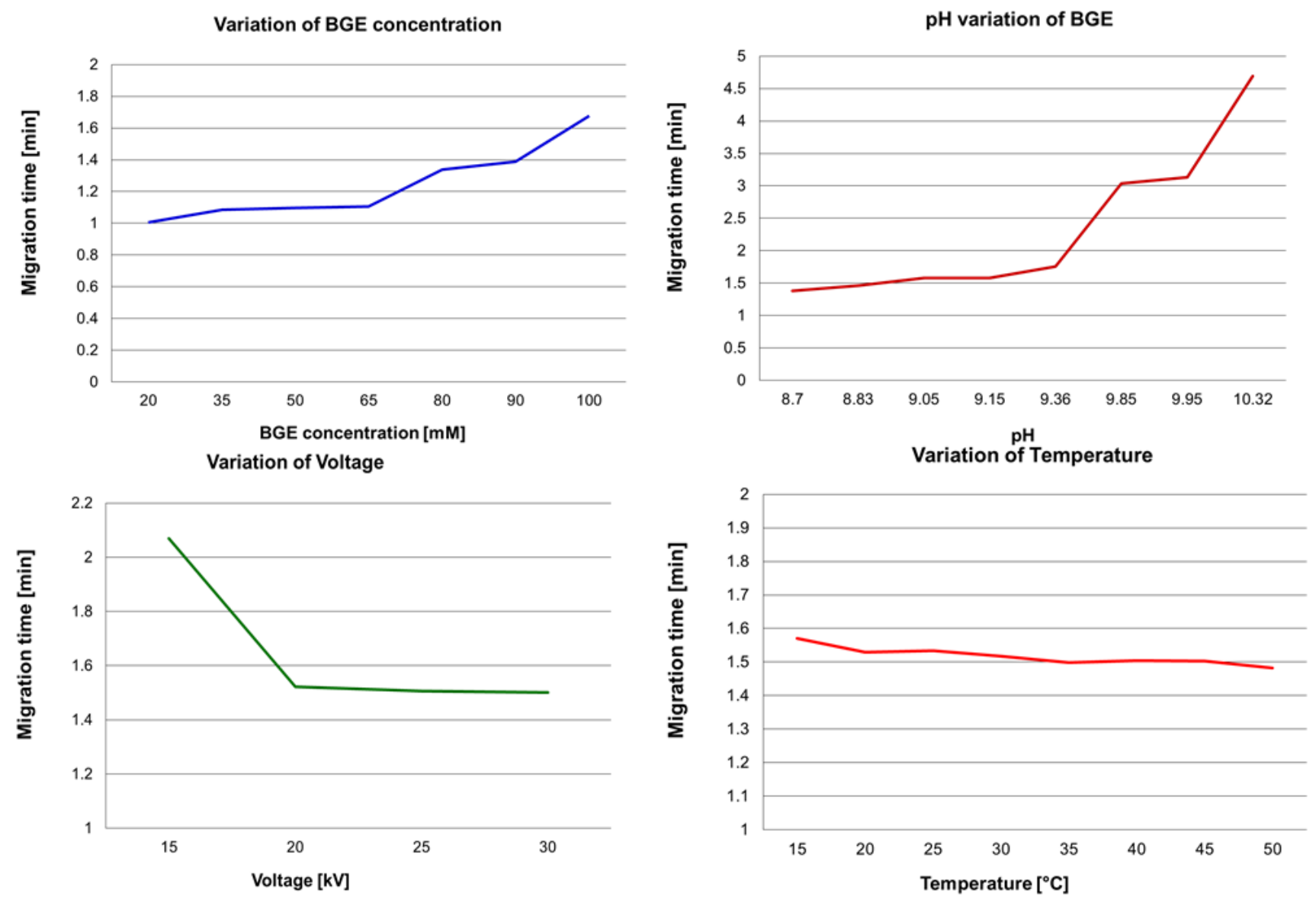

Fig. 3. Variation of the migration time depending on the A) BGE concentration (applied voltage: $+20 \mathrm{kV}$, temperature: $25^{\circ} \mathrm{C}$, injection pressure $30 \mathrm{mbar} / 2 \mathrm{sec}$ ); B) pH of BGE (BGE $90 \mathrm{mM}$ borax, applied voltage: $+20 \mathrm{kV}$, temperature: $25^{\circ} \mathrm{C}$, injection pressure $30 \mathrm{mbar} / 2 \mathrm{sec}$ ); C) voltage (BGE $90 \mathrm{mM}$ borax, temperature: $25^{\circ} \mathrm{C}$, injection pressure $30 \mathrm{mbar} / 2 \mathrm{sec}$ ); $\mathrm{D}$ ) temperature (BGE $90 \mathrm{mM}$ borax, applied voltage: + $20 \mathrm{kV}$, injection pressure $30 \mathrm{mbar} / 2 \mathrm{sec})$. 
and $1 \mathrm{M}$ boric acid in BGE. The LET migration times increased with $\mathrm{pH}$ values. At higher $\mathrm{pH}$ values the registered peaks were very broad. In consequence, the optimum $\mathrm{pH}$ of BGE was set at value 9.36.

Effect of Voltage. The migration times decreased with the increase of voltage so that we set the optimum value at $20 \mathrm{kV}$ to obtain good peak shapes and amplitudes.

Effect of Temperature. Regarding the influence of temperature on LET migration times slightly decreased with the increase of cassette temperature, the limiting factors being the BGE viscosity and the Joule heating which are directly connected with temperature. The temperature was selected at $50^{\circ} \mathrm{C}$ for best shape and high value of the LET peak.

Effect of Injection Pressure and Time. Hydrodynamic injection mode because is more precise and robust than electrokinetic injection. In general, analysts prefer hydrodynamic to electrokinetic injection, especially when analyzing biological matrices (e.g. plasma or urine) with varying composition and conductivity [29].

Injection pressure and time modify the migration time of the analyes, but we have noticed that these parameters have influence on the shape of the peaks. Thus, a high injection pressure $(50 \mathrm{mbar})$ and a short injection time (2s) were preferred in order to avoid peak splitting or broadening.

It was established that LET can be determinate in a very short time, less than 2 minutes (Figure 4). To obtain the best peak shapes with the shortest analysis time, $90 \mathrm{mM}$ borax, $20 \mathrm{kV}$ voltage, $50^{\circ} \mathrm{C}, 50 \mathrm{mbar}$ pressure, 2 seconds injection time and $50{ }^{\circ} \mathrm{C}$ were set as optimum parameters.

CZE method validation. The method was validated and validation parameters were calculated (Table I). The selected internal standard was CIP, a stable compound with a good signal on sodium borate BGE, which migrates after LET and EOF [34].

Specificity. LET could be quantified from tablets without any interference with other present components.
Linearity. The linearity response for LET was assessed in the range $5-875 \mu \mathrm{g} \mathrm{mL}^{-1}$. The linear regression equations were calculated using six concentration levels and three replicates per concentration. Correlation was over 0.99, which demonstrates a good linearity of the method. LOD and LOQ parameters were calculated by using the signalto-noise ratio 3:1 and 10:1, respectively.

Precision. The repeatability of migration time and peak area measurement was performed by six replicate injections containing $62.5 \mu \mathrm{g} \cdot \mathrm{mL}^{-1}$ of LET, three consecutive days.

These results prove that our developed CZE method can be applied for identification and quantitative determination of LET from bulk materials. Until now, on a base of detailed literature survey, it was found that LET could be estimated along with other compounds only by MEKC [16-19].

Determination of LET in tablets. A total of 20 tablets were weighed and powdered. An equivalent of about $10 \mathrm{mg}$ LET was weighed accurately and transferred into a

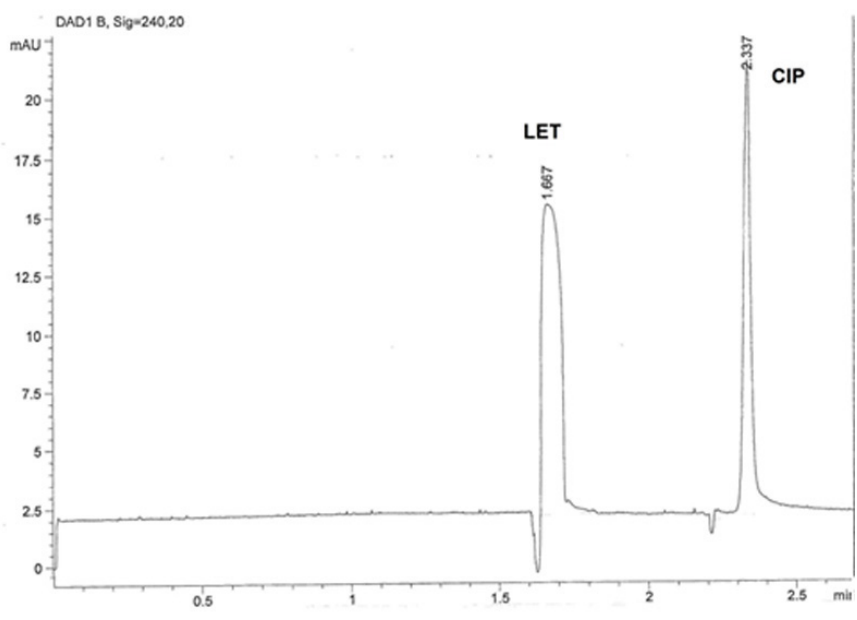

Fig. 4. Electrophoregram of LET. Working parameters: BGE $90 \mathrm{mM}$ borax, $20 \mathrm{kV}$ applied voltage, $50 \mathrm{mbar} / 2$ seconds pressure, temperature $50^{\circ} \mathrm{C}$, UV detection at $240 \mathrm{~nm}$, capillary: $32.5 \mathrm{~cm}(24.5$ $\mathrm{cm}$ effective length) $\times 50 \mu \mathrm{m}$, LET concentration: $62.5 \mu \mathrm{g} \cdot \mathrm{mL}^{-1}$, internal standard CIP concentration $125 \mu \mathrm{g} \cdot \mathrm{mL}^{-1}$.

Table I. Statistical parameters of CZE method

(working concentration range: $5-875 \mu \mathrm{g} \cdot \mathrm{mL}^{-1}$, internal standard CIP) $(\mathrm{T}=$ migration time, $\mathrm{A}=$ area, $\mathrm{H}=$ height)

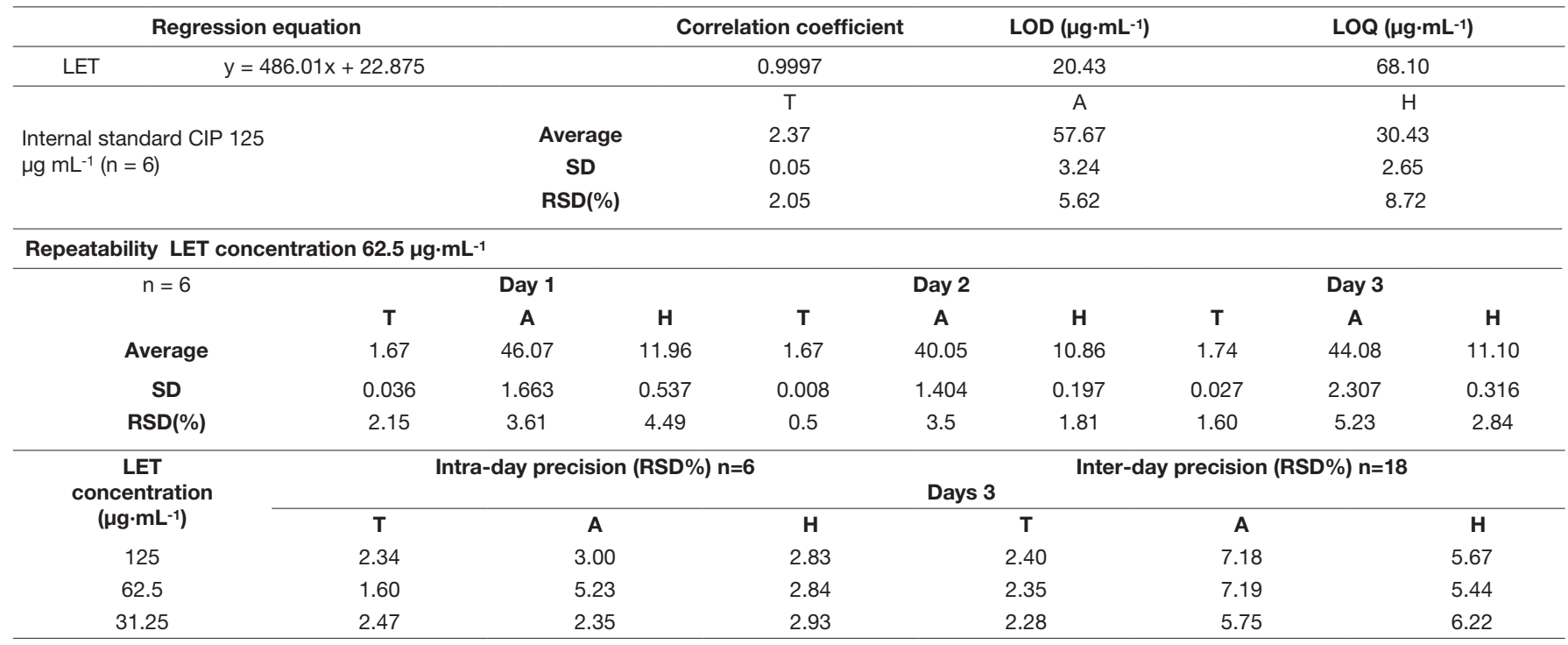


$100 \mathrm{~mL}$ volumetric flask with $50 \mathrm{~mL}$ methanol. After 30 minutes ultrasonic vibration, the mixture was diluted to volume with methanol and then filtrated. A concentration of $100 \mu \mathrm{g} \cdot \mathrm{mL}^{-1}$ of LET was set. The amount of LET from pharmaceutical tablets and standard deviation (SD) were calculated using linear regression equation of the standard curve (Table I) [26]. The recovery (\%) from pharmaceutical formulation was $99.63 \pm 1.51$ (average of three replicates). Therefore our method has potential to be successfully used to determine LET from counterfeit drugs.

Determination of LET from spiked urine samples. Analytical performance of our CZE method was evaluated on spiked urine from healthy volunteers.

Specificity. LET could be quantified from spiked urine samples without any interference with other present urine components (Figure 5).

Linearity and detection limits. The linearity response and detection limits for spiked with LET urine samples are presented in Table II.

The linear regression equations were calculated using six concentration levels and three replicates per concentration. Correlation was over 0.99 , which demonstrates a very good linearity of the method.

Precision. The precision of our CZE method was investigated in repeatability and intermediate precision terms for migration times and peak areas of LET in spiked urine samples (Table II).

Regarding determination of LET our result was satisfactory as respect to selectivity and had a short migration time.

Our validated CZE method is therefore simple but also reliable, with the potential of being used to determinate LET in bulk material, pharmaceutical formulations, counterfeit medicines and urine samples.

\section{B. UV spectrophotometry method}

The UV spectra of samples were recorded in methanol in according with data previously reported from literature [25-28].

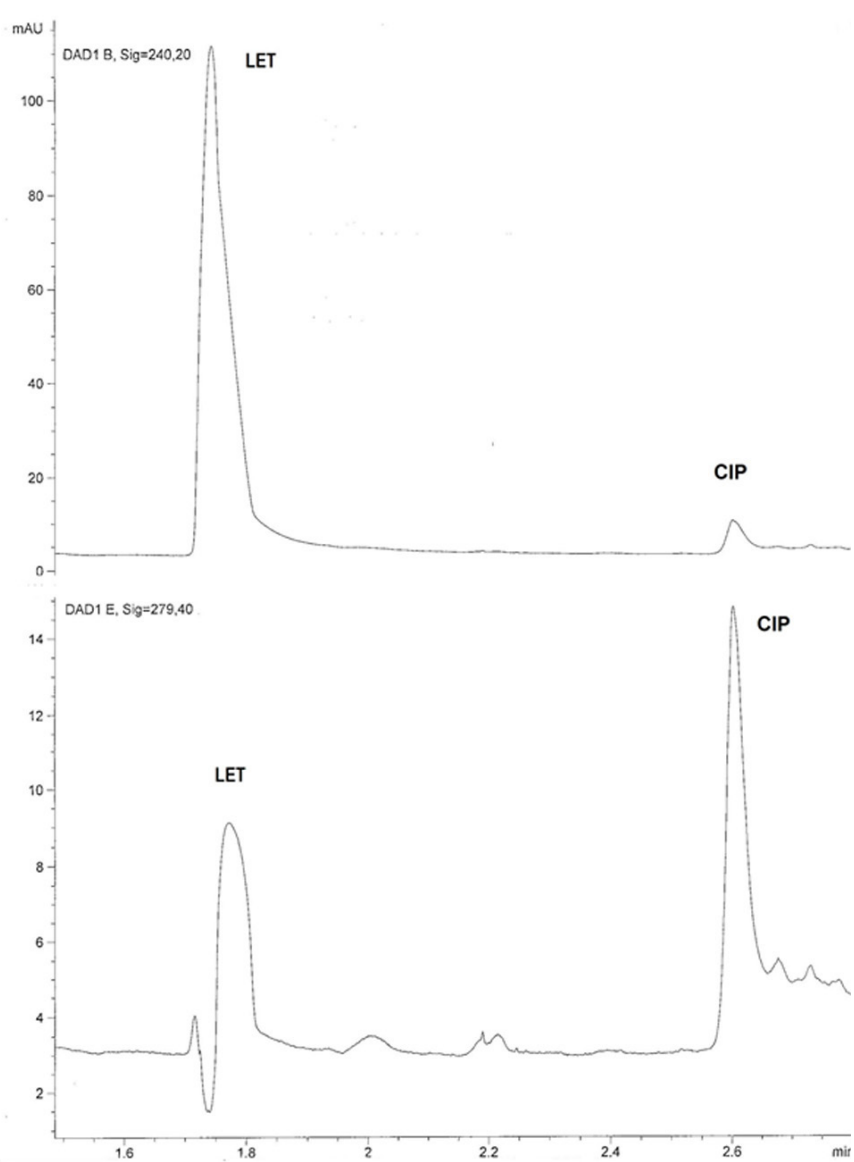

Fig. 5. Electrophoregram of LET form spiked urine sample (LET concentration: $25 \mu \mathrm{g} \cdot \mathrm{mL}^{-1}$, internal standard CIP concentration 50 $\left.\mu \mathrm{g} \cdot \mathrm{mL}^{-1}\right)$, UV detection at $240 \mathrm{~nm}$ and $279 \mathrm{~nm}$. Working parameters: BGE $90 \mathrm{mM}$ sodium tetraborate, $20 \mathrm{kV}$ applied voltage, 150 $\mu \mathrm{A}$ current, $50 \mathrm{mbar} / 2$ seconds pressure, temperature $50^{\circ} \mathrm{C}$, capillary: $32.5 \mathrm{~cm}$ ( $24.5 \mathrm{~cm}$ effective length) $\times 50 \mu \mathrm{m}$.

Determination of $\lambda_{\max }(\mathrm{nm})$. A $10 \mu \mathrm{g} \cdot \mathrm{mL}^{-1}$ concentration was prepared from II stock solution by dilution with methanol. This solution was then scanned at wavelength of 190 to $500 \mathrm{~nm}$ against blank (methanol). The $\lambda_{\max }$ was found to be at $240 \mathrm{~nm}$. Hence this was considered as

Table II. Statistical parameters of the CZE method for LET determination from urine spiked samples, internal standard CIP (T - migration time, $\mathrm{A}$ - area, $\mathrm{H}=$ height).

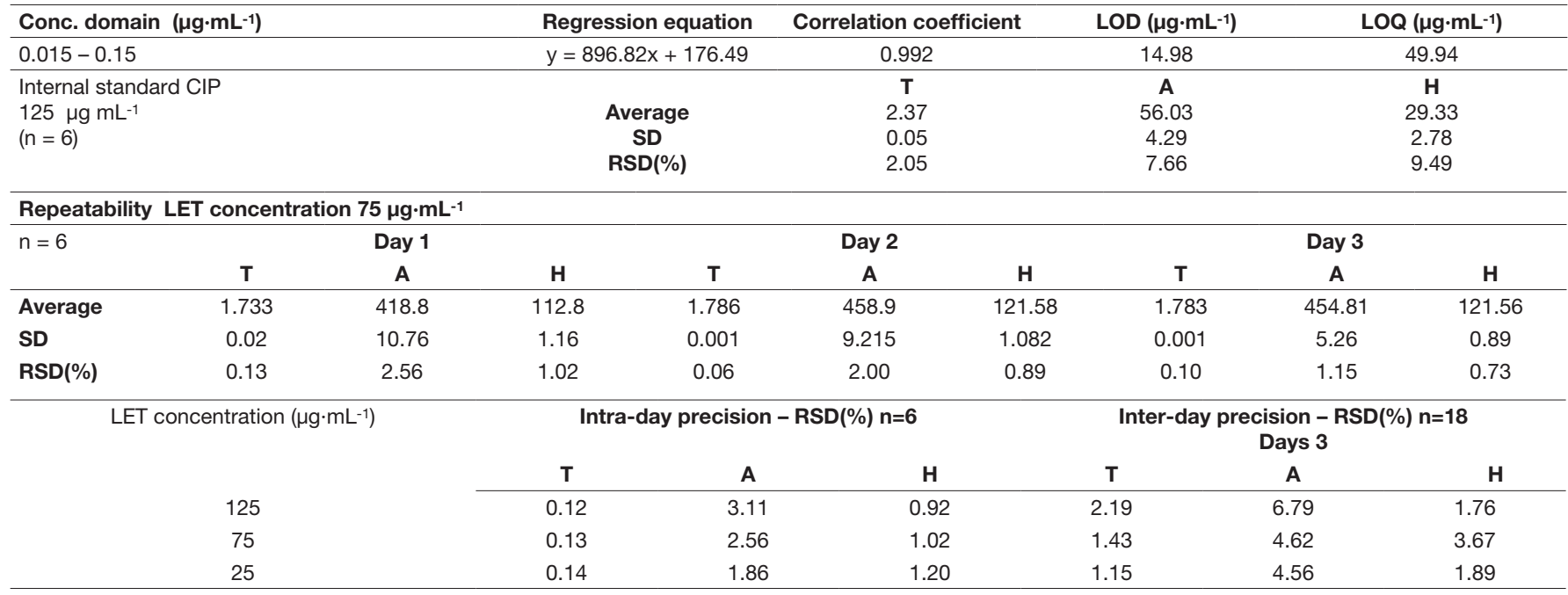


Table III. Statistical parameters of the UV spectrophotometric method for LET

\begin{tabular}{|c|c|c|c|c|c|c|}
\hline \multirow{2}{*}{$\begin{array}{c}\text { Conc. domain }\left(\boldsymbol{\mu g} \cdot \mathrm{mL}^{-1}\right) \\
0.005-0.020\end{array}$} & \multirow{2}{*}{$\begin{array}{c}\text { Regression equation } \\
\mathrm{y}=0.1114 \mathrm{x}-0.0239\end{array}$} & \multicolumn{2}{|c|}{ Correlation coefficient } & \multicolumn{2}{|c|}{ LOD $\left(\mu \mathrm{g} \cdot \mathrm{mL}^{-1}\right)$} & $\mathrm{LOQ}\left(\mu \mathrm{g} \cdot \mathrm{mL}^{-1}\right)$ \\
\hline & & & 986 & & & 29 \\
\hline & \multicolumn{3}{|c|}{ Intra-day precision $n=6$} & \multicolumn{3}{|c|}{$\begin{array}{c}\text { Inter-day precision } \mathrm{n}=18 \\
\text { Days } 3\end{array}$} \\
\hline LET concentration $\left(\mu \mathrm{g} \cdot \mathrm{mL}^{-1}\right)$ & Mean & SD & RSD(\%) & Mean & SD & RSD(\%) \\
\hline 7.0 & 0.738 & 0.010 & 1.35 & 0.761 & 0.022 & 2.94 \\
\hline 10.0 & 0.976 & 0.010 & 1.02 & 1.014 & 0.035 & 3.46 \\
\hline 13.0 & 1.360 & 0.015 & 1.14 & 1.389 & 0.025 & 1.79 \\
\hline
\end{tabular}

absorption maxima which was then used for the calibration curve.

\section{Preparation of standard stock solution}

I Stock solution. LET standard solution was prepared by dissolving $10 \mathrm{mg}$ of LET in $10 \mathrm{~mL}$ methanol $\left(1 \mathrm{mg} \cdot \mathrm{mL}^{-1}\right.$ concentration).

II Stock solution. From I stock solution $1 \mathrm{~mL}$ solution was taken and then diluted up $10 \mathrm{~mL}$ with the same solvent in a volumetric flask $\left(100 \mu \mathrm{g} \cdot \mathrm{mL}^{-1}\right.$ concentration).

Linearity study. From II stock solution aliquots were prepared in the range of $5-20 \mu \mathrm{g} \cdot \mathrm{mL}^{-1}$. The absorbances were measured at $240 \mathrm{~nm}$ and used for the linearity calibration plot (Table III). Our experimental detection limits were set between 1 and $30 \mu \mathrm{g} \cdot \mathrm{mL}^{-1}$.

Intra-day and inter-day precision study. Aliquots of II stock solution were taken and respectively diluted to obtain three concentrations of $7.0,10.0$ and $13 \mu \mathrm{g} \cdot \mathrm{mL}^{-1}$, respectively. Triplicate absorbance measurements of each sample were registered and the mean, SD and RSD calculated. The selected concentrations for intra-day precision study were again analyzed the following 2 days and the standard deviation (SD) and relative standard deviation (RSD) were calculated (Table III).

\section{Determination of LET in tablets}

For the determination of LET from commercial preparation we prepare the samples similar to previous CZE method [26]. The recovery (\%) from pharmaceutical formulation Letrozol was $97.8 \pm 0.098$ (average of three replicates).

\section{Conclusions}

CZE was proven to be a simple, rapid and appropriate method to quantify LET from bulk material, pharmaceutical preparations and spiked urine samples. The analytical parameters were optimized to achieve the determination of LET in a very short time analysis using a $90 \mathrm{mM}$ borax BGE. Validation parameters were also determined, linearity, LOD, LOQ, inter-day and intra-day precision. Also for comparing results a simple, rapid and sensible UV spectrophotometric method for determination of LET in bulk material and pharmaceutical dosage form has been developed and validated. Our methods could be useful in analyzing LET in the pharmaceutical industry, clinical studies and have potential in identifying counterfeit products marketed on-line used by athletes that doping.

\section{Acknowledgement}

The study was supported by a project funded through Internal Research Grants (grant contract for execution of research projects no. 17/23.12.2014) by the University of Medicine and Pharmacy of Tîrgu Mures, Romania.

\section{Conflict of interest}

None to declare.

\section{References}

1. Bhatnagar AS, Häusler A, Schieweck K, Lang M, Bowman R Highly selective inhibition of estrogen biosynthesis by CGS 20267, a new non-steroidal aromatase inhibitor. J Steroid Biochem Mol Biol. 1990;37:1021-1027.

2. Bhatnagar AS - The discovery and mechanism of action of letrozole. Breast Cancer Res Tr. 2007;105(Suppl 1):7-17.

3. Santen RJ, Harvey HA - Use of aromatase inhibitors in breast carcinoma. Endocr-Relat Cancer. 1999;6:75-92.

4. Torrisi R, Rota S, Losurdo A, Zuradelli M, Masci G, Santoro A Aromatase inhibitors in premenopause: Great expectations fulfilled? Crit Rev Oncol Hematol. 2016;107:82-89.

5. Berry $\mathrm{J}$ - Are all aromatase inhibitors the same? A review of controlled clinical trials in breast cancer. Clin Ther. 2005;27:1671-1684.

6. Vari CE, Ösz BE, Miklos A, Berbecaru-lovan A, Tero-Vescan A Aromatase inhibitors in men - off-label use, misuse, abuse and doping, Farmacia, 2016;64: 813-818.

7. Baron DA, Martin DM, Abol Magd S - Doping in sports and its spread to at-risk populations: an international review. World Psychiatry. 2007;6:118-123.

8. Sioufi A, Gauducheau N, Pineau V et al. - Absolute bioavailability of letrozole in healthy postmenopausal women. Biopharm Drug Dispos. 1997; 18:779-789.

9. Sioufi A, Sandrenan N, Godbillon J, et al. - Comparative bioavailability of letrozole under fed and fasting conditions in 12 healthy subjects after a $2.5 \mathrm{mg}$ single oral administration. Biopharm. Drug Dispos. 1997;18:489-497.

10. Tao X, Piao H, Canney DJ, Borenstein MR, Nnane IP - Biotransformation of letrozole in rat liver microsomes: effects of gender and tamoxifen. J Pharm Biomed Anal. 2007;43:1078-1085.

11. Desta Z, Kreutz Y, Nguyen AT, et al. - Plasma letrozole concentrations in postmenopausal women with breast cancer are associated with CYP2A6 genetic variants, body mass index, and age. Clin Pharmacol Ther. 2011;90:693-700.

12. Precht JC, Schroth W, Klein K, et al. -The letrozole phase 1 metabolite carbinol as a novel probe drug for UGT2B7. Drug Metab Dispos. 2013;4:1906-1913.

13. Pfister CU, Martoni A, Zamagni C, et al. - Effect of age and single versus multiple dose pharmacokinetics of letrozole (Femara) in breast cancer patients. Biopharm Drug Dispos. 2001;22:191-197.

14. Letrozole, BCCancer Agency Cancer Drug Manual, Developed: 2001, Page 1-5, Limited revision: 1 May 2006; 1 November 2010, 1 April 2011 (http://www.bccancer.bc.ca/drug-database-site/Drug\%20Index/ Letrozole_monograph_1April2011.pdf Accessed 14 May 2017)

15. Femara (http://www.accessdata.fda.gov/drugsatfda_docs/ nda/97/20726_FEMARA\%202.5MG_BIOPHARMR.PDF Accessed 14 May 2017)

16. Rodríguez Flores J, Berzas Nevado JJ, Castañeda Peñalvo G, Rodríguez Cáceres Ml - Micellar electrokinetic capillary chromatographic method for simultaneous determination of drugs used to treat advanced breast cancer, Chromatographia. 2002;56:283-288. 
17. Rodríguez-Flores J, Contento Salcedo AM, Villaseñor Llerena MJ, Muñoz Fernández L - Micellar electrokinetic chromatographic screening of letrozole and its metabolite in human urine: validation and robustness/ ruggedness evaluation. Electrophoresis. 2008;29:811-818.

18. Rodríguez Flores J, Salcedo AM, Llerena MJ, Fernández LM - Micellar electrokinetic chromatographic method for the determination of letrozole, citalopram and their metabolites in human urine. J Chromatogr A. 2008;1185:281-290.

19. Rodríguez-Flores J, Contento Salcedo AM, Muñoz Fernández L. Rapid quantitative analysis of letrozole, fluoxetine and their metabolites in biological and environmental samples by MEKC. Electrophoresis. 2009;30:624-632.

20. Suntornsuk L - Recent advances of capillary electrophoresis in pharmaceutical analysis. Anal Bioanal Chem. 2010; 398:29-52.

21. Zarghi A, Foroutan SM, Shafaati A, Khoddam A. - HPLC Determination of Letrozole in Plasma Using Fluorescence Detection: Application to Pharmacokinetic Studies. Chromatographia. 2007;66: 747-750.

22. Mondal N, Pal TK, Ghosal SK - Development and validation of RP-HPLC method to determine letrozole in different pharmaceutical formulations and its application to studies of drug release from nanoparticles. Acta Pol Pharm. 2009;66:11-17.

23. Shao R, Yu LY, Lou HG, Ruan ZR, Jiang B, Chen JL - Development and validation of a rapid LC-MS/MS method to quantify letrozole in human plasma and its application to therapeutic drug monitoring. Biomed Chromatogr. 2016;30:632-637.

24. Vanol PG, Singhal, P, Shah PA, Shah JV, Shrivastav PS, Sanyal M - SPEUPLC-MS/MS assay for determination of letrozole in human plasma and its application to bioequivalence study in healthy postmenopausal Indian women. JPA. 2016;6:276-281.
25. Mondal N, Pal TK, Ghosal SK - Development and Validation of a Spectrophotometric Method for Estimation of Letrozole in Bulk and Pharmaceutical Formulation, Pharmazie. 2007;62:597-598

26. Acharjya SK, Mallick P, Panda P, Kumar KR, Annapurna MM Spectrophotometric methods for the determination of letrozole in bulk and pharmaceutical dosage forms. J Adv Pharm Tech Res. 2010;1:348353.

27. Patil SM, Galatage ST, Choudhary AU - Development of UV spectrophotometric method for estimation of letrozole in pure and pharmaceutical dosage form, Indo American Journal of Pharmaceutical Research. 2013;3:5541-5548.

28. UV and IR Spectra, Pharmaceutical Substances (UV and IR) and Pharmaceutical and Cosmetic Excipients (IR), in Dibbern HW, Müller RM, Wirbitzki E(eds): Editio Cantor Verlag, Aulendor, 2002, 873.

29. Mayer BX - How to increase precision in capillary electrophoresis. J Chromatogr A. 2001;907:21-37.

30. Letrozole - DrugBank (https://www.drugbank.ca/drugs/DB01006 Accessed 14 May 2017)

31. MarvinSketch - ChemAxon (https://www.chemaxon.com/products/ marvin/marvinsketch/ )

32. Orlandini S, Gotti R, Furlanetto S - Multivariate optimization of capillary electrophoresis methods: a critical review. J Pharm Biomed Anal. 2014;87:290-307.

33. Varenne A, Descroix S - Recent strategies to improve resolution in capillary electrophoresis-A review, Anal Chim Acta. 2008;628:9-23.

34. Rusu A, Hancu G, Völgyi G, Tóth G, Noszál B, Gyéresi A - Separation and determination of quinolone antibacterials by capillary electrophoresis. J Chromatogr Sci. 2014;52:919-925. 